\title{
Preferential inhibition of hepatocellular carcinoma by the flavonoid Baicalein through blocking MEK-ERK signaling
}

\author{
RONG-RUI LIANG ${ }^{1 *}$, SHU ZHANG ${ }^{1,2^{*}}$, JUN-AN QI $^{1,3}$, ZHI-DONG WANG $^{1}$, JUN LI $^{4}$, PEI-JUN LIU ${ }^{4}$, \\ CHEN HUANG ${ }^{4,5}$, XIAO-FENG LE ${ }^{2}$, JUN YANG $^{4}$ and ZONG-FANG LI ${ }^{1,4,5}$ \\ ${ }^{1}$ Department of General Surgery, Second Affiliated Hospital, School of Medicine, \\ Xi'an Jiaotong University, Xi'an 710004, P.R. China; ${ }^{2}$ Department of Experimental Therapeutics, \\ The University of Texas M.D. Anderson Cancer Center, Houston, TX 77030, USA; \\ ${ }^{3}$ Department of General Surgery, Baoji Central Hospital, Baoji 721008; ${ }^{4}$ Engineering Research Center of \\ Biotherapy and Translational Medicine of Shaanxi Province, Xi'an Jiaotong University, Xi'an; \\ ${ }^{5}$ Key Laboratory of Environment and Genes Related to Diseases of the Education Ministry, \\ School of Medicine, Xi'an Jiaotong University, Shaanxi, Xi'an 710061, P.R. China
}

Received March 10, 2012; Accepted May 18, 2012

DOI: $10.3892 /$ ijo. 2012.1510

\begin{abstract}
Baicalein is a purified flavonoid extracted from the roots of Scutellaria baicalensis or Scutellaria radix. Although previous studies have suggested that Baicalein possesses an in vitro anti-hepatocellular carcinoma activity, its in vivo effects and mechanisms of action are still not completely understood. In this study, Baicalein at concentrations of $40-120 \mu \mathrm{M}$ exhibited significant cytotoxicity to three hepatocellular carcinoma (HCC) cell lines but marginal cytotoxicity to a normal liver cell line in vitro. Compared to a standard chemotherapy drug, 5-fluorouracil (5-FU), Baicalein had greater effect on HCC cells but less toxicity on normal liver cells. Treatment with Baicalein dramatically reduced mitochondrial transmembrane potential, and activated caspase- 9 and caspase-3. Blockade of Baicaleininduced apoptosis with a pan-caspase inhibitor partially attenuated Baicalein-induced growth inhibition in HCC. Baicalein treatment significantly inhibited tumor growth of HCC xenografts in mice. Induction of apoptosis was
\end{abstract}

Correspondence to: ProfessorZong-Fang Li,Department of General Surgery, The Second Affiliated Hospital, School of Medicine, Xi'an Jiaotong University, 157 West Fifth Road, Shaanxi, Xi'an 710004, P. R. China

E-mail:1zf2568@gmail.com

Dr Jun Yang, Engineering Research Center of Biotherapy and TranslationalMedicine of Shaanxi Province, Xi'an Jiaotong University, Xi'an, P. R. China

E-mail: yangjundr@yahoo.com.cn

*Contributed equally

Key words: Baicalein, hepatocellular carcinoma, MEK, ERK, apoptosis demonstrated in Baicalein-treated xenograft tumors by the terminal deoxynucleotidyl transferase dUTP nick end labeling (TUNEL) assay. Furthermore, Baicalein treatment dramatically decreased the levels of phosphorylation of MEK1, ERK1/2 and Bad in vitro and in vivo. Overexpression of human MEK1 partially blocked Baicalein-induced growth inhibition. Consequently, these findings suggest that Baicalein preferentially inhibits HCC tumor growth through inhibition of MEK-ERK signaling and by inducing intrinsic apoptosis.

\section{Introduction}

Hepatocellular carcinoma (HCC) is one of the common cancers in Asia and Africa. The incidence of HCC is increasing in Europe and the United States (1). Although HCC can be cured at the early stage by surgical resection, most patients can not be diagnosed at the early stage since tumors are asymptomatic (2). Current treatment options for HCC patients at the late stage include chemotherapy, chemoembolization, ablation, and proton beam therapy. These treatment options remain disappointed in clinic. HCC patients will relapse and rapidly progress to the advanced stages with vascular invasion and multiple metastases, which lead to a low 5-year survival rate of less than $7 \%$ (3). HCC patients who have surgically resectable localized tumors show a better prognosis. However, even these patients have a dismal 5-year survival rate of 15 to $39 \%$ (4). Clearly, there is an urgent need to search for new therapies for this lethal disease.

We have reported that chrysanthemum indicum extract (CIE), a Chinese herbal extraction, exerts a significantly inhibitory effect on HCC cells (MHCC97H) in previous studies $(5,6)$. One particular point to stress is that CIE appeares to have no cytotoxic effect on normal liver cells, highlighting an advantage of the herbal treatment. Herbal medicine flavonoids have recently received increasing attention because of the beneficial effects of anti-tumor and 


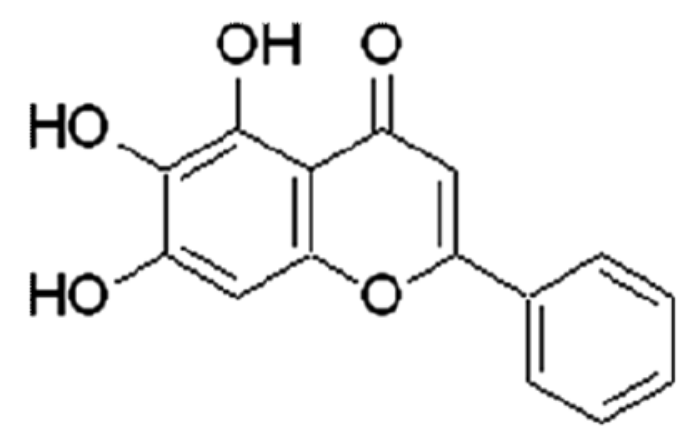

Figure 1. Chemical structures of Baicalein.

as chemopreventive agents (2-5). Baicalein (5,6,7-trihydroxy2-phenyl-4H-1-benzopyran-4-one) is a purified flavonoid with defined chemical structure (Fig. 1) and is extracted from the roots of Scutellaria baicalensis or Scutellaria radix. Although the anti-tumor activity of Baicalein in HCC has been reported in vitro $(7,8)$, little is known about the underlying mechanisms of action on HCC, as well as the anti-tumor effect in vivo.

Previously genetic and expression profiling analyses of human HCC have led to the identification of key oncogenes and tumor-suppressor genes in liver carcinogenesis (9). They are mostly associated with the mitogen-activated protein kinase (MAPK) pathway (9). Constitutively activated extracellular signal-regulated kinases (ERK) have been shown to increase proliferation of human HCC cells (10). So far there is no report that investigates the effects of Baicalein on ERK in HCC. In this study, we have investigated the effects of Baicalein on HCC cells in vitro and in vivo, especially the effects of Baicalein on ERK in HCC. We have demonstrated that inhibition of MAPK/ ERK signaling and induction of apoptosis by Baicalein treatment are critical mechanisms by which Baicalein inhibits HCC growth.

\section{Materials and methods}

Reagents. Baicalein was purchased from Sigma-Aldrich Co. (St. Louis, MO, USA). Dulbecco's modified Eagle's medium (DMEM) was purchased from Invitrogen (Carlsbad, CA, USA). Fetal bovine serum (FBS), penicillin, and streptomycin were ordered from Gibco-BRL (Rockville, MD, USA). The apoptosis detection kit was from Nanjing KeyGen Biotech. Co. Ltd. (Nanjing, China). MTT (3-(4,5-dimethyl-2-thiazole)2,5-diphenyltetrazolium bromide) was purchased from Sigma Chemicals Co. (St. Louis, MO, USA). Caspase inhibitor z-VAD-fmk and anti-cytochrome $c$ were purchased from Beyotime (Haimen, China), anti-MEK1 and anti-PhosphoMEK1 (Thr386) anti-Phospho (Thr386) MEK1 (p-MEK1) were from Millipore Co. (Billerica, MA, USA). Anti-ERK1/2, anti-Phospho (Thr202/Tyr204) ERK1/2 (p-ERK1/2), antiPhospho-MEK1/2 (p-MEK1/2), anti-caspase-3, anti-Bad and anti-Phospho-Bad(Ser112) antibodies were purchased from Cell Signaling Technology Inc. (Danvers, MA, USA).

Animals. Male BALB/c nude mice (4-week-old) were purchased from the Beijing Experimental Animal Center and maintained in the Laboratory Animal Center of Xi'an Jiaotong University, in accordance with the University Institutional Animal Care and Use Committee. $\mathrm{HepG}_{2}$ cells $\left(2 \times 10^{6}\right)$ suspended in $200 \mu \mathrm{l}$ of DMEM were injected subcutaneously into the right inguinal area of the 6-week-old male nude mice. All animals developed palpable tumors. Mice were divided into two groups $(n=6$ per group): group I, treatment with vehicle DMSO as the control group; group II, treatment with $20 \mathrm{mg} / \mathrm{kg} /$ day Baicalein via oral adminitration. Treatments were started one week after the injection of $\mathrm{HepG}_{2} \mathrm{HCC}$ cells. Resulting tumors were measured using a vernier caliper every two days following the tumor cell injections, and tumor volumes were calculated using the formula: volume $=\left(\right.$ length $\mathrm{x}$ width $\left.{ }^{2}\right) / 2$ and expressed as mean size \pm standard error.

Cell culture. Human HCC cell lines $\left(\mathrm{HepG}_{2}, \mathrm{BEL}-7402\right.$, SMMC7721) and human normal liver cell line (HL-7702) were purchased from Shanghai Institute of Cell Biology (Shanghai, China). Cells were cultured in DMEM supplemented with $10 \% \mathrm{FBS}, 100 \mathrm{U} / \mathrm{ml}$ penicillin, $100 \mu \mathrm{g} / \mathrm{ml}$ streptomycin, and $2 \mathrm{mmol} / \mathrm{l}$ glutamine. All cells were incubated at $37^{\circ} \mathrm{C}$ with $5 \% \mathrm{CO}_{2}$.

Construction of expression plasmids and transfection. The full-length pcDNA3.1 (Invitrogen, Paisley, UK) MEK1 vector was made by cloning of the full-length PCR product of MEK1 with KOD ${ }^{\circledR}$ DNA polymerase (Toyobo, Osaka, Japan). All the plasmid sequences were confirmed by DNA sequencing. For transient transfection experiments, cells were plated $24 \mathrm{~h}$ before transfection in a 6-well plate at a density of $2 \times 10^{5}$. Lipofectamine 2000 (Invitrogen) was used to perform transfection with $4.0 \mu \mathrm{g}$ pcDNA3.1(+)-MEK1 vector or $4.0 \mu \mathrm{g}$ pcDNA3.1(+) empty vector (as a negative control) according to the manufacturer's protocol.

Assessment of cell viability and apoptosis. Cell viability was determined by a colorimetric 3-(4,5-dimethylthiazol-2-yl) 2,5-diphenyltetrazolium bromide (MTT) assay as previous reported (11). In brief, after treatment of cells with or without the indicated agent and/or serum for $48 \mathrm{~h}$, the cells were washed twice with PBS and incubated with $0.5 \mathrm{mg} / \mathrm{ml}$ MTT (Sigma) for $4 \mathrm{~h}$. The reagent was absorbed by living cells and eventually formed an insoluble blue formazan product. After the incubation period, cells were washed with PBS, solubilized with dimethyl sulfoxide (DMSO), and quantified using a microplate reader at the absorbance of $550 \mathrm{~nm}$. The inhibition rate was determined using SPSS software (version 17.0, SPSS Inc, Chicago, IL, USA).

Apoptotic and/or necrotic cells were evaluated by Annexin $\mathrm{V}$ binding and propidium iodide (PI) uptake using an Annexin V-FITC/PI kit as previously described (12). Briefly, tumor cells were plated at a density of $1 \times 10^{5}$ cells per well into 6-well plates for $24 \mathrm{~h}$. The cells were treated with various concentrations of Baicalein $(0,40,80$ and $120 \mu \mathrm{M})$ and incubated at $37^{\circ} \mathrm{C}$ for 24 and $48 \mathrm{~h}$. The cells were washed with cold PBS and resuspended in Annexin V binding buffer. The cells were stained with Annexin V-FITC for 15 min, washed, and then stained with PI. The samples were analyzed by flow cytometer with CellQuest software.

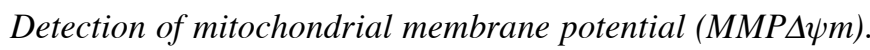
Loss of MMP $\Delta \psi \mathrm{m}$ was assessed by flow cytometry, using a fluorescent indicator Rh123, as previously described $(13,14)$. 
Briefly, cells were treated with Baicalein at different concentrations $(0,20,40$ and $60 \mu \mathrm{M})$ for $24 \mathrm{~h}$. Then, Rh123 working solution was added to the culture at a final concentration of $2 \mu \mathrm{g} / \mathrm{ml}$ and then incubated in the dark at $37^{\circ} \mathrm{C}$ for $30 \mathrm{~min}$. Cells were then washed with PBS, and fluorescence of Rh123 was detected immediately using a FACSCalibur, at an excitation wavelength of $488 \mathrm{~nm}$ and an emission wavelength of $525 \mathrm{~nm}$.

Caspase-3 and caspase-9 activity assay. Cell lysates were prepared by incubating $2 \times 10^{6}$ cells $/ \mathrm{ml}$ in extraction buffer (25 mM Tris- $\mathrm{mCl}, \mathrm{pH} 7.5,20 \mathrm{mM} \mathrm{MgCl}_{2}$, and $150 \mathrm{mM} \mathrm{NaCl}$, $1 \%$ Triton $\mathrm{X}-100,25 \mu \mathrm{g} / \mathrm{ml}$ leupeptin, and $25 \mu \mathrm{g} / \mathrm{ml}$ aprotinin) for $30 \mathrm{~min}$ on ice. Lysates were centrifuged at $12,000 \mathrm{x} \mathrm{g}$ for $15 \mathrm{~min}$. Cellular extracts $(30 \mu \mathrm{g})$ were then incubated in a 96-well microtitre plate with 20 ng Ac-DEVD-pNA (caspase-3 activity) or Ac-LEHD-pNA (caspase-9 activity) (Beyotime) for $2 \mathrm{~h}$ at $37^{\circ} \mathrm{C}$. Caspase activity was measured by cleavage of the Ac-DEVD-pNA or Ac-LEHD-pNA substrate to pNA, the absorbance of which was measured at $405 \mathrm{~nm}$. Relative caspase activity was calculated as a ratio of emission of treated cells to untreated cells.

Western blot analysis. Western blot analysis was executed as previously described (15). Whole-cell extracts were prepared from Baicalein-treated or control-treated cells cultured in 6-well plates. After incubation, cells were harvested and resuspended in lysis buffer, washed with ice-cold PBS and lysed in extraction buffer $(40 \mathrm{mmol} / \mathrm{l}$ Tris-HCl, $\mathrm{pH} 7.5,150 \mathrm{mmol} / \mathrm{l} \mathrm{KCl}, 1 \mathrm{mmol} / \mathrm{l}$ EDTA, $1 \%$ Triton X-100, $100 \mathrm{mmol} / 1 \mathrm{NaVO}_{3}, 1 \mathrm{mmol} / 1 \mathrm{PMSF}$ ) supplemented with the protease inhibitor cocktail. The protein $(50 \mu \mathrm{g})$ was separated on 10\% SDS-PAGE and transferred onto PVDF membranes. The membranes were blocked with $5 \%$ non-fat milk in Tris-buffered saline (TBS) at $37^{\circ} \mathrm{C}$, and then incubated with rabbit anti-MEK1 antibody $(1: 1,000)$, rabbit anti-p-MEK1 antibody (1:1,000), mouse anti-ERK1/2 antibody $(1: 1,000)$, rabbit anti-p-ERK1/2 antibody $(1: 1,000)$, rabbit antiBad antibody $(1: 1,000)$, rabbit anti-p-Bad antibody $(1: 1,000)$ or mouse anti- $\beta$-actin antibody (1:500) in TBS containing $5 \%$ non-fat milk for $12 \mathrm{~h}$ at $4^{\circ} \mathrm{C}$. Horseradish peroxidase-linked anti-mouse $\operatorname{IgG}(1: 5,000)$ or horseradish peroxidase-linked antirabbit IgG $(1: 5,000)$ was used as a secondary antibody (in TBS containing 5\% non-fat milk for $3 \mathrm{~h}$ at room temperature), and antigen-antibody complexes were detected using an enhanced chemiluminescence kit (Amersham, ECL Plus, Freiburg, Germany). Densitometry values for western blot analysis and antibody array experiments were estimated by the ImageQuant TL software (GE Healthcare, Buckinghamshire, UK) and expressed as arbitrary units (a.u.). Multiple film exposures were used to verify the linearity of the samples analyzed and to avoid saturation of the film.

Immunohistochemical procedures. The expressions and intracellular localizations of MAPK/ERK in HCC and mice xenograft were examined immunohistochemically. Antigen retrieval was performed by microwave oven for $15 \mathrm{~min}$ in TEG buffer (10 mM Tris, $0.5 \mathrm{mM}$ ethylene glycol tetraacetic acid, $\mathrm{pH}$ 9.0). Incubation with primary antibody for $60 \mathrm{~min}$ at room temperature was followed by detection of the primary antibody using the Advance ${ }^{\mathrm{TM}}$ HRP system (Dako). The chromogen 3,3'-diaminobenzidine was applied and all the staining was performed using the Autostainer Plus Link Instrument (Dako). After washing, the slides were counterstained with Meyer's hematoxylin for $30 \mathrm{sec}$. The following antibodies were used: p-MEK1/2 (dilution factor 1:100), pERK1/2 (dilution factor 1:100), PCNA (dilution factor 1:100). All antibodies mentioned above were from Cell Signaling Technology.

Terminal dUTP nick end labeling (TUNEL) analysis. Xenograft tumors were resected and fixed in formalin for $24 \mathrm{~h}$, and imbedded in paraffin and 5-micron of sections were prepared. TUNEL assay was performed using an apoptag peroxidase in situ apoptosis detection kit (Chemicon International, Temecula, CA, USA). Briefly, the sections were digested using proteinase $\mathrm{K}$ and the endogenous peroxidase activity was blocked using 3\% hydrogen peroxide in PBS. The sections were then placed in equilibration buffer and incubated with working strength of TdT enzyme in a humidifying chamber at $37^{\circ} \mathrm{C}$ for $1 \mathrm{~h}$. The reaction was terminated with a stop/wash buffer provided with the kit. The apoptotic nuclei were stained by direct immunoperoxidase detection of digioxigeninlabeled DNA in test sections.

Statistical analysis. Data are presented as the mean \pm standard errors from at least three independent experiments and analyzed using Student's t-test. $\mathrm{p}<0.05$ was considered statistically significant. All statistical tests and corresponding p-values were two sided.

\section{Results}

Baicalein preferentially inhibits HCC cells and spares normal liver cells. In order to investigate whether or not Baicalein has any differential cytotoxicity to HCC and normal liver cells as CIE does $(5,6)$. We examined the cytotoxic activity of Baicalein in three $\mathrm{HCC}$ lines $\left(\mathrm{HepG}_{2}, \mathrm{BEL}-7402\right.$ and SMMC-7721) and one normal liver cell line (HL-7702). The anti-tumor effects of Baicalein were examined by an MTT assay after treatment with 20 to $120 \mu \mathrm{M}$ of Baicalein for 48 or $72 \mathrm{~h}$. As shown in Fig. 2A, the viability of $\mathrm{HepG}_{2}$, BEL-7402 and SMMC-7721 cells was significantly reduced by Baicalein treatment in a time- and dose-dependent manner, whereas the normal liver cell line (HL-7702) was hardly affected. To further examine the cytotoxicity of Baicalein in $\mathrm{HepG}_{2} \mathrm{HCC}$ cells and normal liver HL-7702 cells, 5-FU was used as a treatment benchmark in comparison with Baicalein. While 5-FU had a 50\% inhibiting concentration $\left(\mathrm{IC}_{50}\right)$ of $1.05 \mathrm{mM}$ in $\mathrm{HepG}_{2}$ cells, Baicalein had an $\mathrm{IC}_{50}$ value of $68.32 \mu \mathrm{M}$ (Fig. 2B). As shown in Fig. 2B, the inhibitory effect of Baicalein on HL-7702 normal liver cells at its $\mathrm{IC}_{50}$ concentration was significantly lower than that of 5-FU at its $\mathrm{IC}_{50}$ concentration. Baicalein had an inhibition rate of $5.43 \% \pm 1.00 \%$, whereas $5-\mathrm{FU}$ inhibited more than $35 \%$ on normal liver cells at its $\mathrm{IC}_{50}$ concentration in normal liver cells (Fig. 2B).

\section{Baicalein reduces mitochondrial transmembrane potential and induces intrinsic apoptosis. To explore the mechanisms by which Baicalein inhibits $\mathrm{HCC}$ growth, $\mathrm{HepG}_{2} \mathrm{HCC}$ cells were first examined by phase contrast microscopy for any apoptotic characteristics after incubation with Baicalein at different}


A

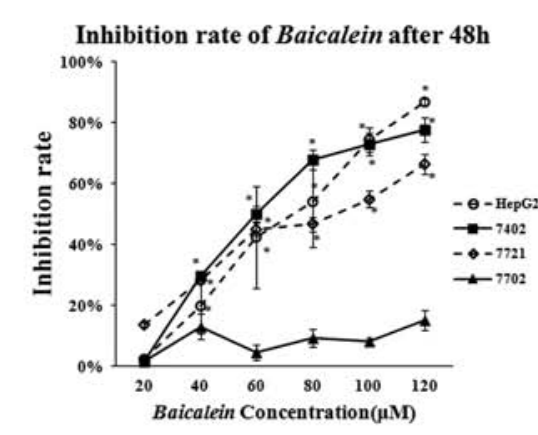

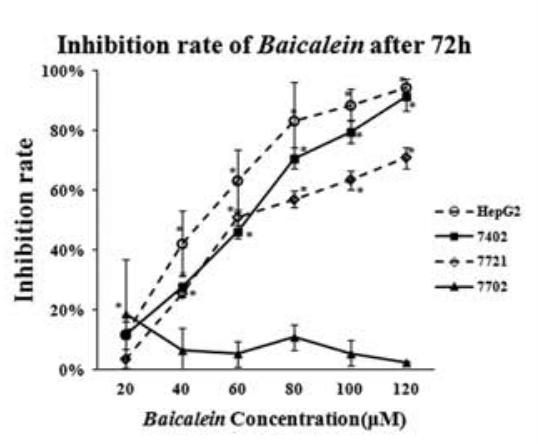

B

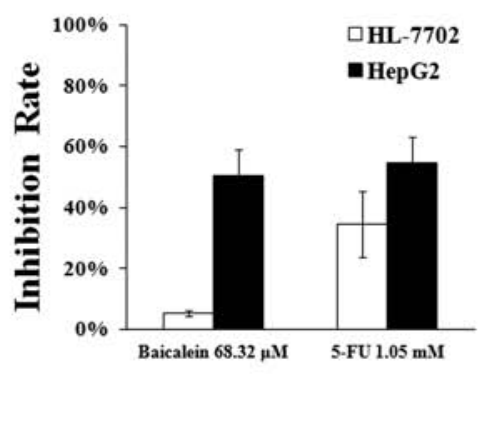

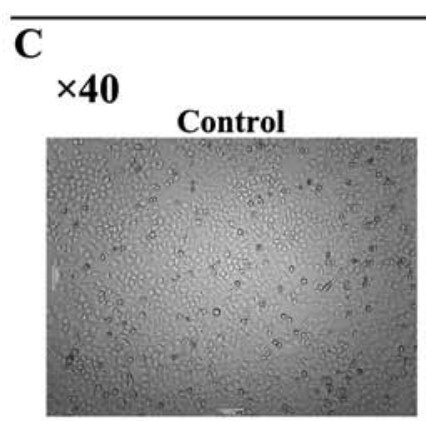

$80 \mu \mathrm{M}$

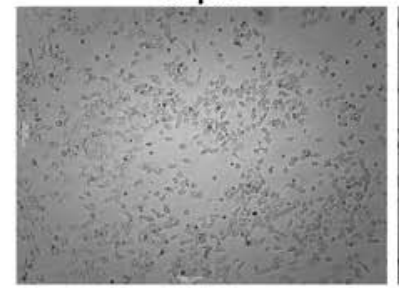

$40 \mu \mathrm{M}$

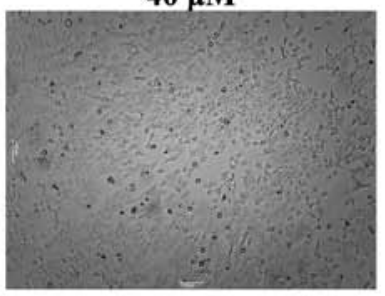

$120 \mu \mathrm{M}$

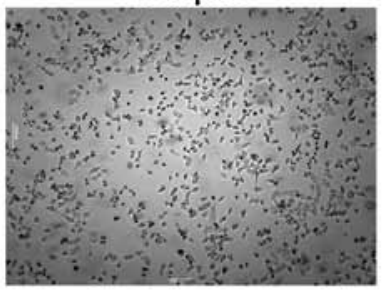

$\times 200$

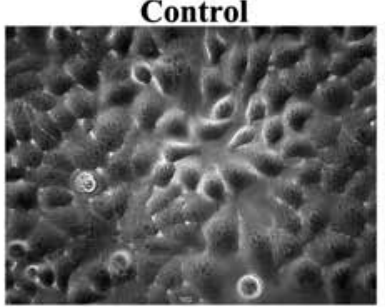

$80 \mu \mathrm{M}$

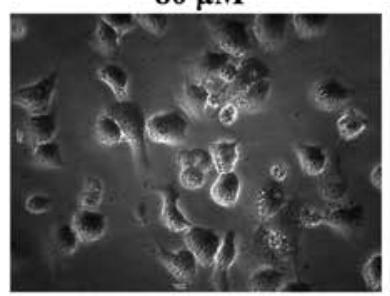

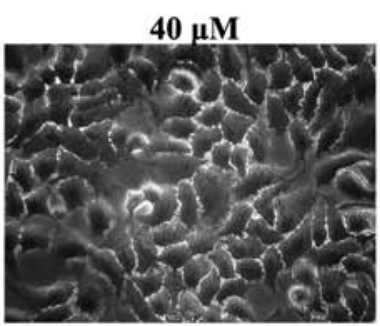

$120 \mu \mathrm{M}$

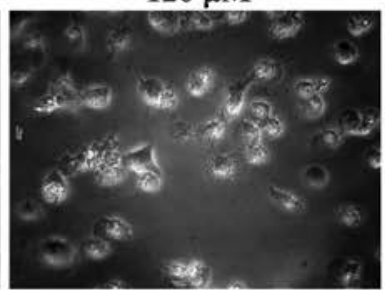

Figure 2. Baicalein preferentially inhibits HCC cells. (A) Effects of Baicalein on hepatocellular cells (HepG ${ }_{2}$, BEL-7402, SMMC-7721) and normal liver cells (HL-7702). The cell viability was measured by MTT assay. Points, mean; bars, SE; " $\mathrm{p}<0.05$ significant difference vs control. Y-axis, inhibiting rate, was determined in assay repeated at least three times in duplicate. (B) Effects of Baicalein and 5-Fluorouracil (5-FU) on normal HL-7702 cells and HCC HepG2 cells. 5-FU was used as a positive control. " $\mathrm{p}<0.05$ significant difference vs control. (C) Baicalein-induced morphological changes in $\mathrm{HepG}_{2}$ cells. Control cells and cells treated with 40, 80 and $120 \mu \mathrm{M}$ Baicalein for $48 \mathrm{~h}$ (x40 and $\times 200)$ were observed and photographed by a phase contrast microscope.

concentrations $(0,40,80,120 \mu \mathrm{M})$ for $24 \mathrm{~h}$. As shown in Fig. 2C, the control-treated cells showed a typical polygonal and intact appearance, whereas the Baicalein-treated cells displayed cellular shrinkage $(40,80 \mu \mathrm{M})$, rounding $(120 \mu \mathrm{M})$, poor adherence $(120 \mu \mathrm{M})$ and round floating shapes $(120 \mu \mathrm{M})$. To determine the effect of Baicalein on apoptosis in detail, $\mathrm{HepG}_{2} \mathrm{HCC}$ cells were treated with different concentrations of Baicalein (40, 80 or $120 \mu \mathrm{M}$ ), for $24 \mathrm{~h}$ and then subjected to an Annexin $\mathrm{V}$ analysis on flow cytometry. As shown in Fig. 3A, Baicalein induced marked apoptosis in $\mathrm{HepG}_{2}$ cells in a concentration-dependent manner. After short treatment for $24 \mathrm{~h}$, the numbers of early apoptotic cells accompanied some late apoptotic cells were significantly increased in the Baicalein-treated $\mathrm{HepG}_{2}$ cells when compared with controltreated $\mathrm{HepG}_{2}$ cells (Fig. 3A). After longer treatment for $48 \mathrm{~h}$, the numbers of late apoptotic and necrotic cells were also dramatically increased along with early apoptotic cells in the Baicalein-treated $\mathrm{HepG}_{2}$ cells (Fig. 3A).

The decrease of mitochondrial transmembrane potential (MMP $\Delta \psi \mathrm{m})$ has been reported as an early event of apoptosis (16) and can be detected by the decline of rhodamine 123 fluorescence. To determine whether or not Baicalein- induced apoptosis involves the MMP $\Delta \psi \mathrm{m}$, we used a fluorescent indicator Rh123 to detect the MMP $\Delta \psi \mathrm{m}$ in $\mathrm{HepG}_{2}$ cells that were treated with $20-60 \mu \mathrm{M}$ of Baicalein for $24 \mathrm{~h}$. As shown in Fig. 3B, after exposure to different doses of Baicalein, the cells exhibited dose-dependent decline of Rho123 staining. At the doses of 40 and $60 \mu \mathrm{M}$, Baicalein-treated cells had significant lower values of rhodamine 123 fluorescence $(3,258.11 \pm 355.90$, $2,705.45 \pm 276.17)$ than the control $(4,703.24 \pm 698.91, \mathrm{p}<0.05)$, further indicating that Baicalein can induce apoptosis in liver cancer cells (Fig. 3B).

To further determine whether apoptosis induced by Baicalein was a mitochondrial-dependent pathway, we tested whether cytochrome $c$ could be released from the mitochondria into the cytoplasm. As shown in Fig. 3C, levels of cytochrome $c$ release from the mitochondria increased dose-dependently in the Baicalein-treated $\mathrm{HepG}_{2}$ cells at concentrations ranging from 40 to $120 \mu \mathrm{M}$. To further investigate whether apoptosis induced by Baicalein was a caspase-dependent pathway, we tested whether mitochondrial-related caspases were activated by Baicalein treatment. Our research showed that caspase- 9 and caspase- 3 activities were highly increased dose-dependently on exposure to Baicalein in $\mathrm{HepG}_{2}$ cells 
$\mathbf{A}$

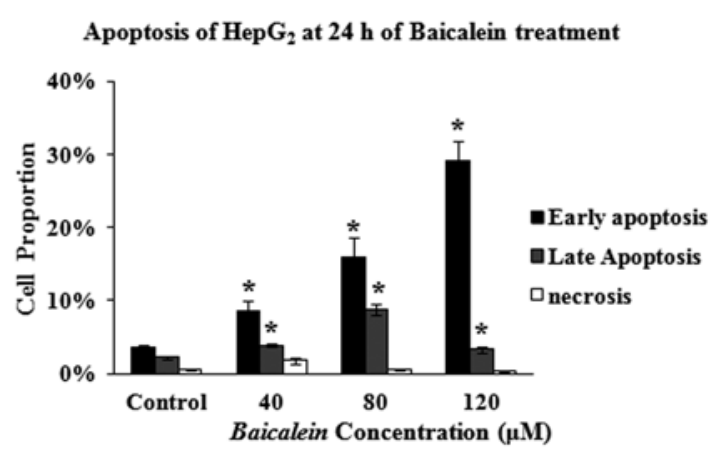

Apoptosis of $\mathrm{HepG}_{2}$ at $\mathbf{4 8}$ h of Baicalein treatment

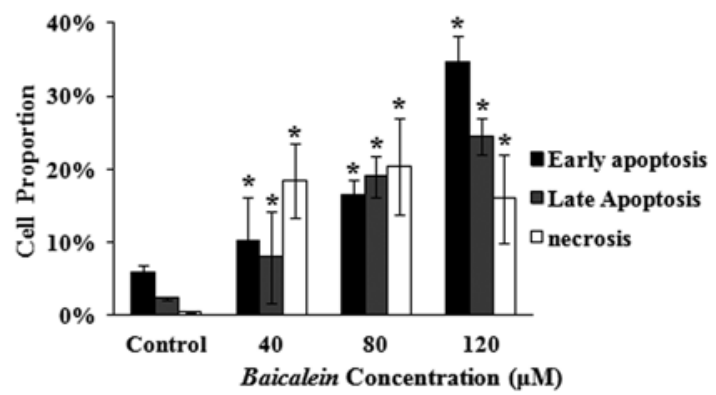

B

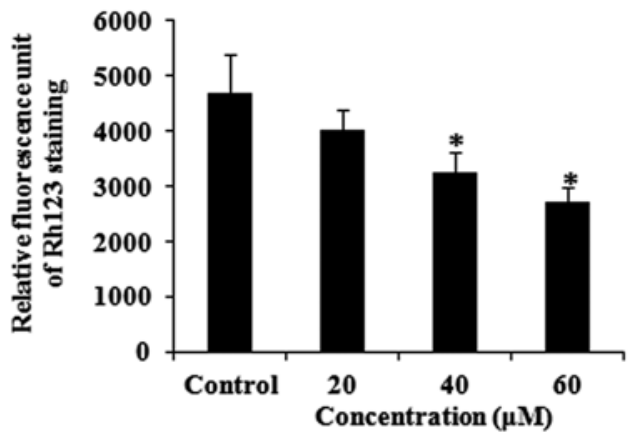

C

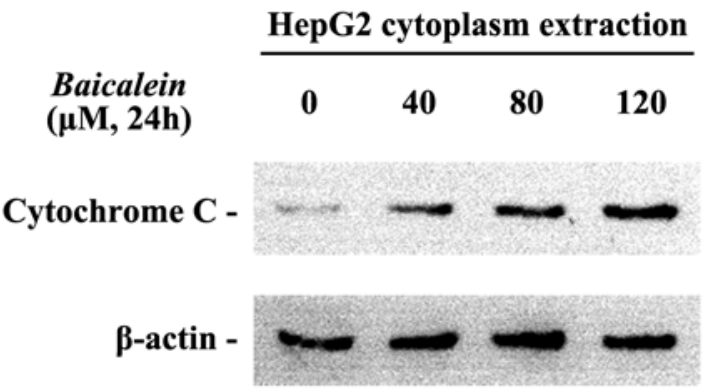

D
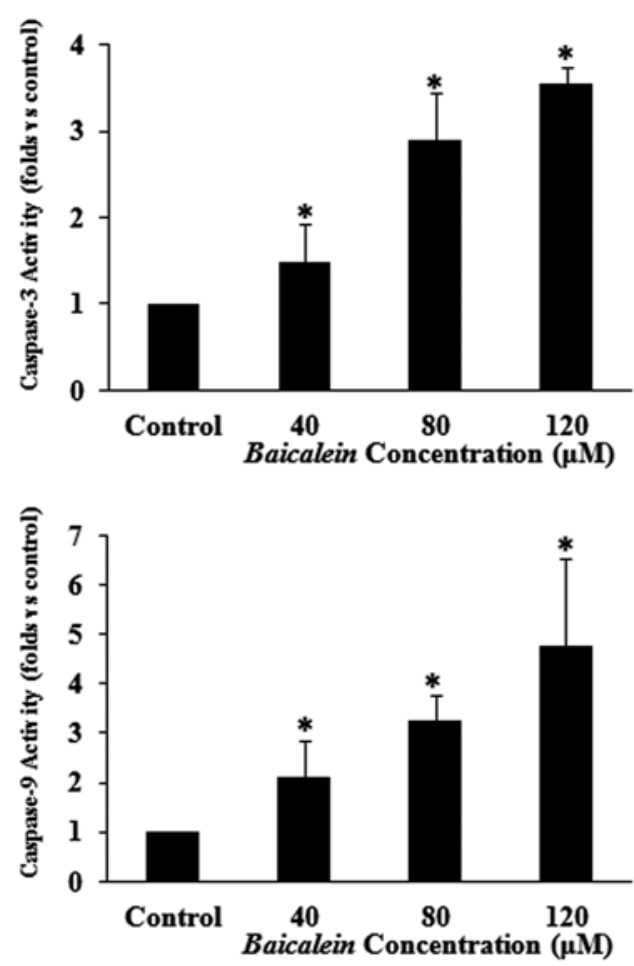

$\mathbf{E}$

$\mathrm{HepG}_{2}-\mathbf{4 8 h}$

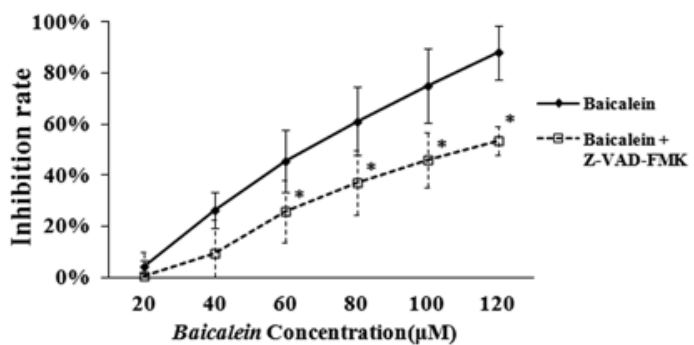

$\mathrm{HepG}_{2}-\mathbf{7 2 h}$

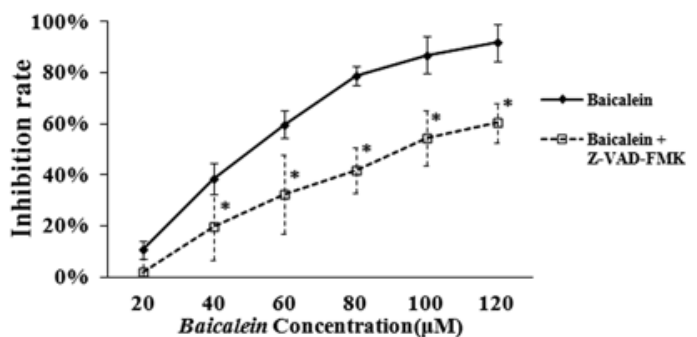

Figure 3. Baicalein induces intrinsic apoptosis in $\mathrm{HCC}$ cells and inhibition of apoptosis partially blocks Baicalein-induced growth inhibition. $\mathrm{HepG}_{2}$ cells were treated with Baicalein at indicated concentrations. (A) Detection of Baicalein-induced apoptosis by Annexin V flow cytometry assay. Flow cytometry was performed after 24 and $48 \mathrm{~h}$ of treatment. Induction rate of apoptosis was calculated as percentage of Annexin V+/PI+ cells in HepG ${ }_{2}$. Early apoptotic cells, late apoptotic cells and necrotic cells were measured according to manufacturer's protocol. ${ }^{*} \mathrm{p}<0.05$ significant difference vs control. This assay was repeated three times in duplicate. (B) Detection of Baicalein-induced apoptosis by mitochondrial membrane potential (MMP $\Delta \psi \mathrm{m}) . \mathrm{MMP} \Delta \psi \mathrm{m}$ of $\mathrm{HepG}$ cells was determined by flow cytometry $24 \mathrm{~h}$ after Baicalein treatment. Results presented are representative of 3 independent experiments. M1, HCC cells contained Rho123 in cytoplasm; M2, HCC cells contained Rho123 in mitochondria; " $\mathrm{p}<0.05$ vs control group. (C) Detection of Baicalein-induced apoptosis by cytochrome $c$ release. Cytochrome $c$ release into the cytoplasm was detected by western blot analysis. (D) Detection of Baicalein-induced apoptosis by caspase 3/9 activity. Caspase 3/9 activities were detected by commercially available ELISA kits as described in Materials and methods. (E) Role of Baicalein-induced apoptosis on growth inhibition of $\mathrm{HepG}_{2}$ cells treated with Baicalein in the presence of $10 \mu \mathrm{M}$ pan-caspase inhibitor z-VAD-fmk or DMSO as a control. " $\mathrm{p}<0.05$ vs control.

(Fig. 3E). Furthermore, we treated $\mathrm{HepG}_{2}$ cells with Baicalein in the presence of $10 \mathrm{M}$ pan-caspase inhibitor (z-VAD-fmk) or DMSO (as a control). MTT assay showed that z-VAD-fmk partially attenuated Baicalein-induced inhibition on $\mathrm{HepG}_{2}$ cells (Fig. 3D), suggesting that apoptosis induction is an important cause for Baicalein-induced growth inhibition in HCC. 


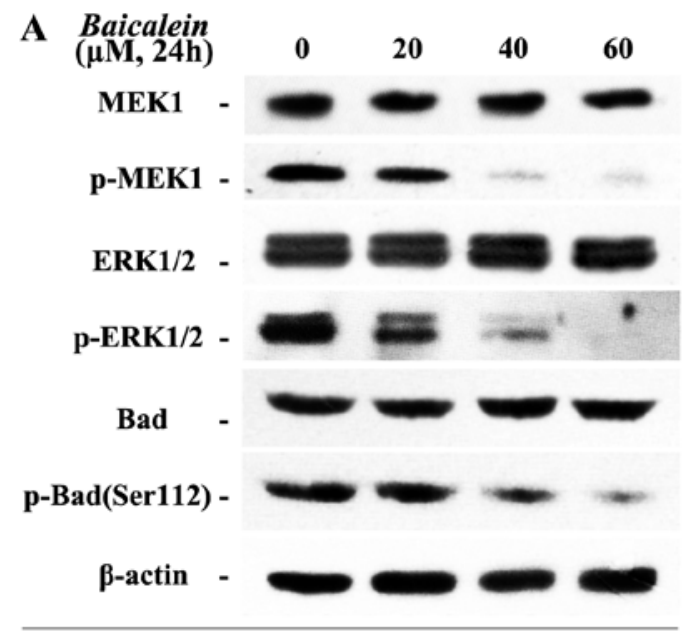

C
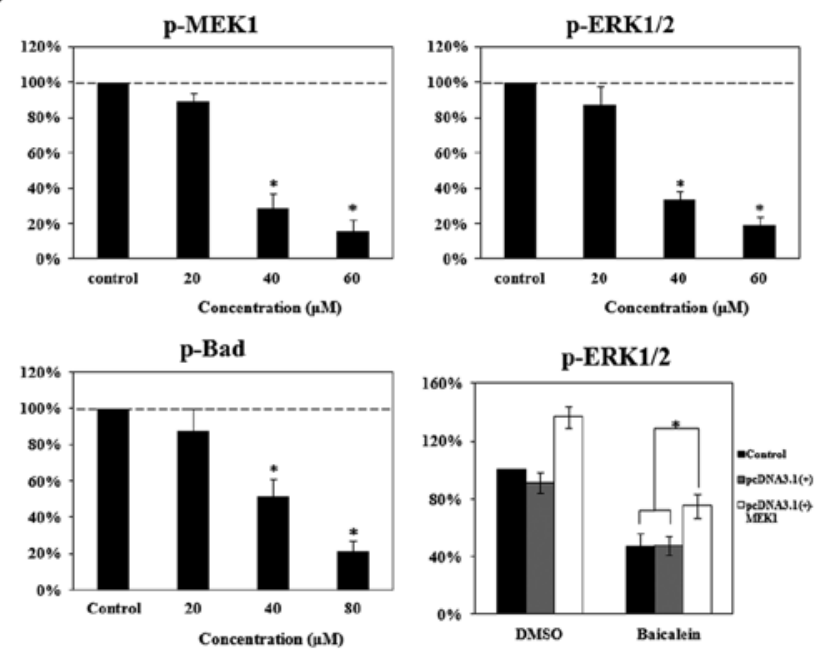

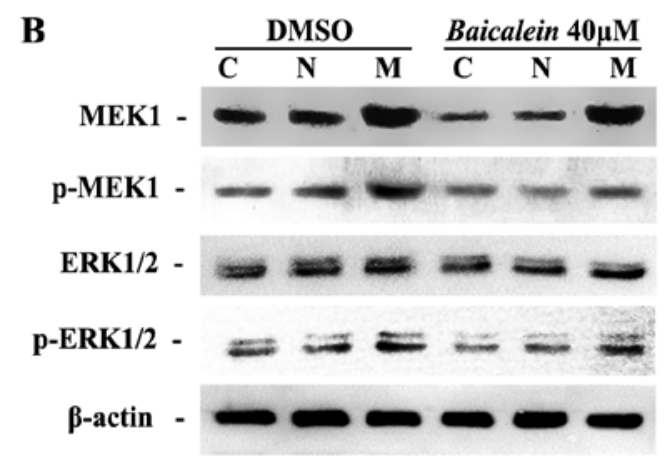

C: Control; N: peDNA3.1(+); M: pcDNA3.1(+)-MEK1.

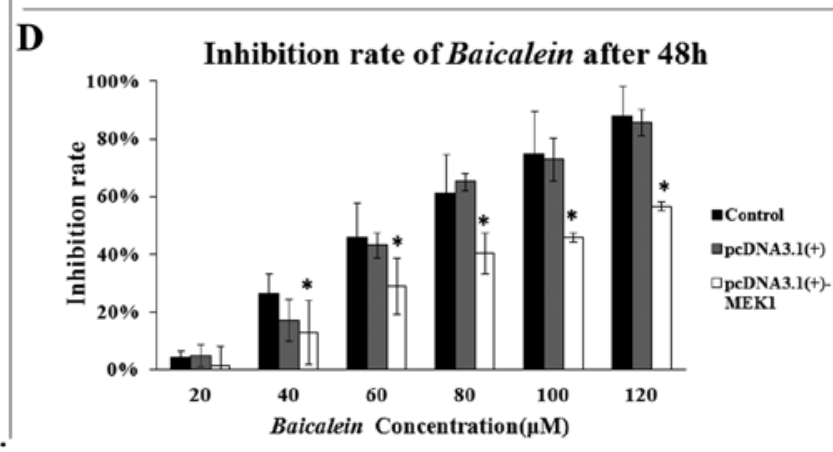

Figure 4. Baicalein downregulates MAPK/ERK signaling and enforces expression of MEK1 partially blocks Baicalein-induced growth inhibition. HepG ${ }_{2}$ cells were treated with Baicalein at indicated concentrations. (A) Levels of total-MEK and ERK1/2 and phospho-MEK and ERK1/2 as well as total-Bad, phospho-Bad

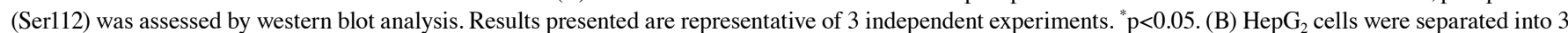
groups: no treatment as the control group ' $\mathrm{C}$ ', transfected with an empty vector pcDNA3.1(+) as the negative control group 'N', transfected with a pcDNA3.1(+)MEK1 as the positive group 'M'. Western blot analysis was performed to detect MAPK/ERK activity in three groups of cells with or without Baicalein treatment. (C) Phosphorylation densities of MEK1, ERK1/2 and Bad were digitally scanned. Results presented are representative of 3 independent experiments. ${ }^{*}$ p $<0.05$ vs control group. (D) MTT assays were executed to evaluate Baicalein-induced inhibitory effect on three groups of cells. * $\mathrm{p}<0.05$ vs control group.

Baicalein inhibits MEK/ERK signaling in vitro. Western blot analysis has been utilized to evaluate the effect of Baicalein on phosphorylation levels of MEK and ERK in $\mathrm{HepG}_{2}$ cells. As shown in Fig. 4A and 4C, Baicalein inhibited MEK1 and ERK1/2 phosphorylation at a concentration-dependent manner in $\mathrm{HepG}_{2}$ cells. The phosphorylation level of $\mathrm{Bad}$ (Ser 112), which is an anti-apoptosis protein activated by the MEK/ERK pathway in tumor cells (17), was also measured $24 \mathrm{~h}$ after Baicalein treatment. Baicalein reduced levels of phosphorylated Bad of Ser 112 in a dose-dependent manner (Fig. 4A and 4C).

Roles of MEK-ERK signaling in Baicalein activity. To determine whether this Baicalein-induced growth inhibition depends on the MEK-ERK pathway, $\mathrm{HepG}_{2}$ cells were transfected with a plasmid pcDNA3.1(+)-MEK1 expressing human MEK1. Ectopic expression of MEK1 led to an enhanced activity of MEK-ERK pathway indicated by increased phosphorylation of MEK1 and ERK1/2 (18) (Fig. 4B). Importantly, HepG cells with ectopic expression of MEK1 (higher MEK-ERK activity) became relatively resistant to Baicalein-induced growth inhibition (Fig. 4). Overexpression of MEK1 partially attenuated Baicalein-induced inhibition of ERK1/2 phosphorylation (Fig. 4C). Overexpression of MEK1, in part, blocked Baicalein-induced growth inhibition in vitro (Fig. 4D). These data suggest that inhibition of MEK-ERK is one of critical mechanism by which Baicalein inhibits HCC cells.

Baicalein suppresses HCCxenograft growth, inhibits MEK-ERK phosphorylation, and induces apoptosis in vivo. In the animal study, the control group received diluent vehicle treatment only, whereas the treatment group received Baicalein $20 \mathrm{mg}$ / $\mathrm{kg} /$ day. This in vivo dosage was selected by our pilot experiments that showed significant tumor inhibition but without significant side effects. The mice were treated with Baicalein daily for 21 days. As shown in Fig. 5A, Baicalein-treated mice exhibited a statistically significant tumor volume reduction $(\mathrm{p}<0.01)$ compared with the control group. The average tumor volume of control and treatment group were $3.25 \pm 0.56 \mathrm{~cm}^{3}$ and $1.02 \pm 0.40 \mathrm{~cm}^{3}$, respectively. After treatment for 21 days, the mice were sacrificed, xenograft tumors were resected and the tumor weight of xenograft were measured. As shown in Fig. 5B and 5C, tumor sizes and weights in Baicalein-treated mice were dramatically smaller than those in control-treated 
A

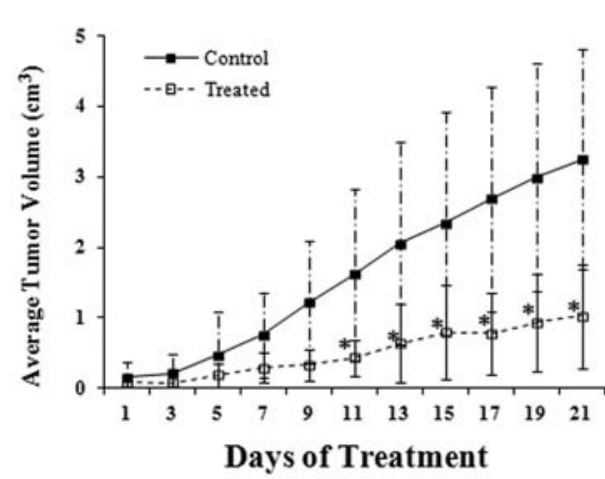

B

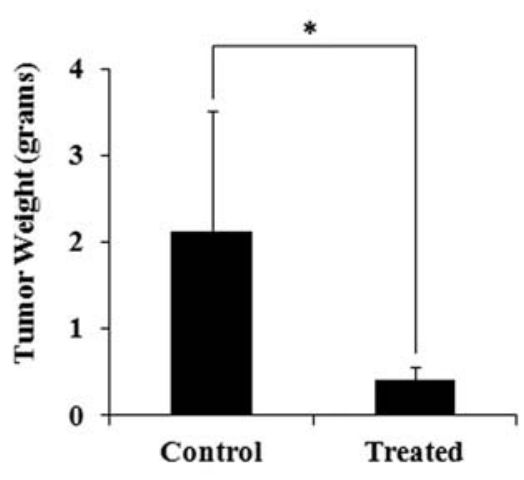

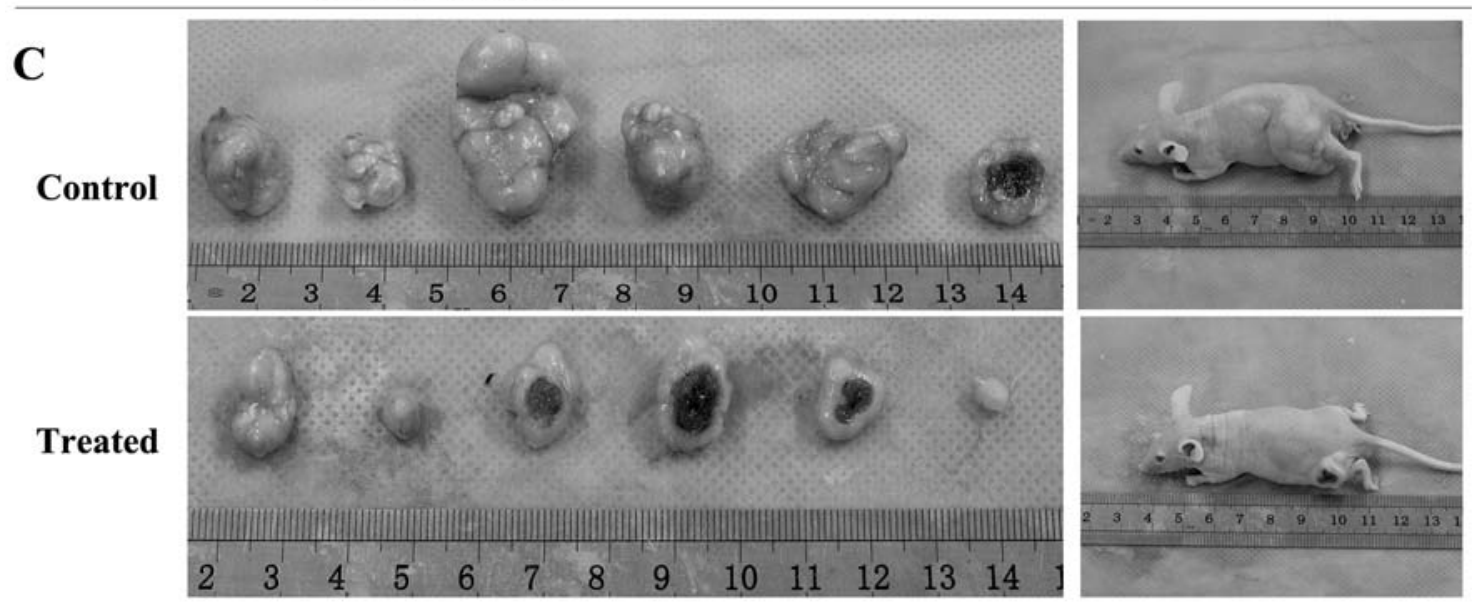

Figure 5. Baicalein suppresses tumor growth in vivo in a $\mathrm{HepG}_{2}$ xenograft model. Mice were equally divided into two groups after one week since HepG $\mathrm{F}_{2}$ cell inoculation. One group of mice were treated with Baicalein $10 \mathrm{mg} / \mathrm{kg} /$ day and another group of mice received vehicle treatment as a control. (A) Xenografts were measured every two days during treatments; tumor volumes were calculated according to the formula: volume $=1$ length $\mathrm{x}$ width ${ }^{2} / 2$. ${ }^{*} \mathrm{p}<0.05 \mathrm{vs}$ control. Significant difference in tumor volumes were detected at different timepoints vs the control. (B) Tumors were allowed to develop for approximately 3 weeks and then animals were sacrificed and all visible tumors were dissected and weighed. ${ }^{*} \mathrm{p}<0.05$ vs control. (C) Morphological images of xenografts after Baicalein treatment for 3 weeks.

mice. The control-treated mice had a median tumor weight of $2.12 \mathrm{~g}$, whereas the Baicalein-treated mice had a median tumor weights of $0.41 \mathrm{~g}$ (Fig. 5B).

In order to confirm the in vitro observation of Baicaleininduced apoptosis (Fig. 3), Baicalein-induced apoptosis in xenograft tumors was evaluated with the terminal deoxynucleotidyl transferase dUTP nick end labeling (TUNEL) assay. As shown in Fig. 6A, Baicalein-treated tumors had greater TUNEL-postive cells than control-treated tumors. In agreement with the in vitro observations, $\mathrm{p}-\mathrm{MEK} 1 / 2$ and $\mathrm{p}$-ERK1/2 expression were markedly inhibited in Baicalein-treated tumors as illustrated by immunohistochemical analysis (Fig. 6A) and western blot analysis (Fig. 6B and 6C). MEK-ERK signaling associated Bad phosphorylation (Serine 112) was also decreased by Baicalein treatment (Fig. 6B and 6C). Above data confirm the in vitro results and show that Baicalein treatment can significantly suppress HCC tumor growth and MEK-ERK signaling, and can induce apoptosis in vivo.

\section{Discussion}

Baicalein alone, or in combination with other herbs, has recently been shown to have cytostatic effect on several cancer cell lines in vitro $(7,19)$ and also in vivo $(20,21)$. Baicalein has shown the advantage of inhibiting the growth of cancer cells while leaving normal cells relatively unaffected in several studies $(22,23)$. In this report, we confirmed that Baicalein had anti-cancer effect against HCC cells in vitro. We have further demonstrated that Baicalein had much lower cytotoxicity to normal liver cells in comparison with 5-FU. 5-FU can be benefitially used for hepatic arterial infusion chemotherapy (24) or intra-peritoneal administration (25) as treatment for HCC. However, toxicity issue limits its clinical application. Our data showed that Baicalein had greater effect on HCC cells but less toxicity on normal liver cells than 5-FU. Thus, Baicalein is potentially more acceptable than 5-FU in clinic and deserves further clinical trials. To our knowledge, this is the first study to evaluate the potential of Baicalein in vivo treatment of $\mathrm{HCC}$ xenografts. Significant reduction of tumor mass was observed after a 3-week treatment. The in vivo effect of Baicalein on HCC tumors strongly support Baicalein as a potential new chemodrug for anti-HCC treatment.

Whether Baicalein inhibits HCC cells via apoptosis induction is still controversial. A high proportion of necrotic HCC cells after Baicalein treatment was observed by Matsuzaki et al (8). Baicalein was also reported to induce caspase-related apoptosis in cancer cells (26). In the present study, we confirmed a pro-apoptotic effect of Baicalein on HCC cells by using several methods. Although it was widely reported that mostly chemotherapy reagent induced mitochondrial 
$\mathbf{A}$
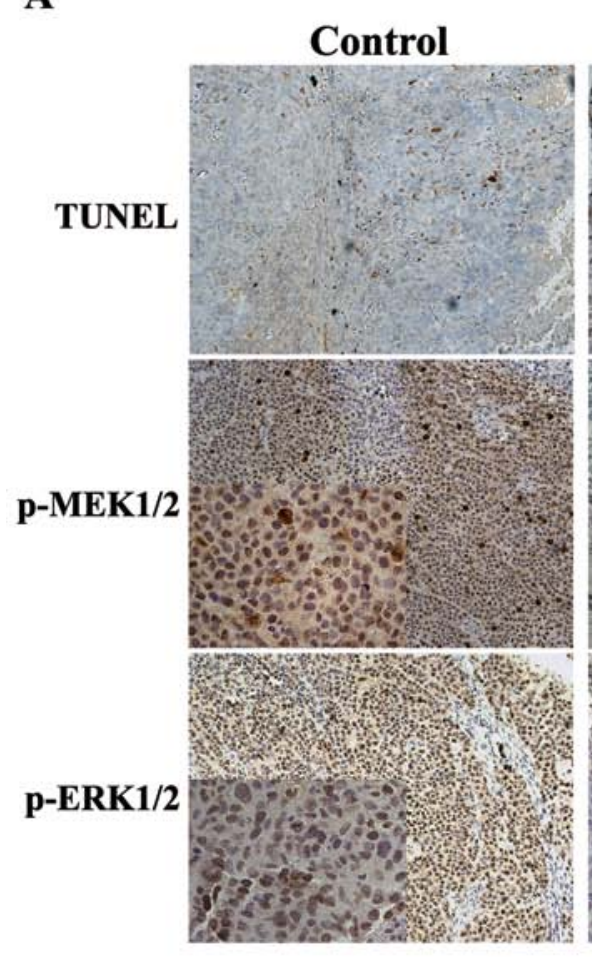

B
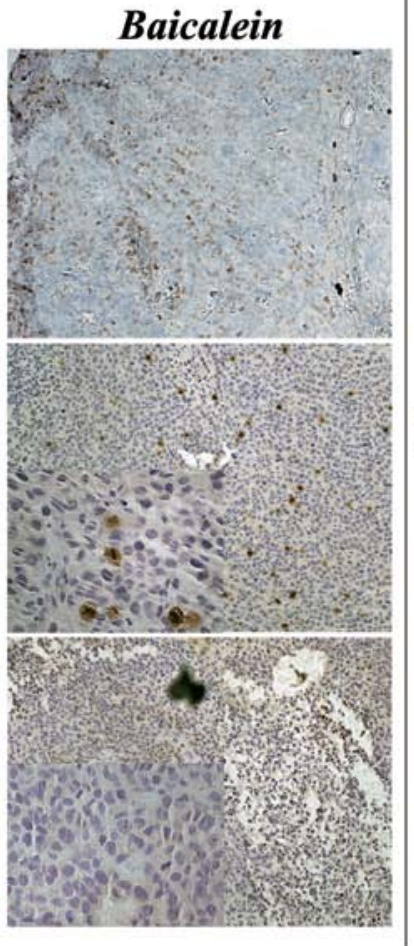

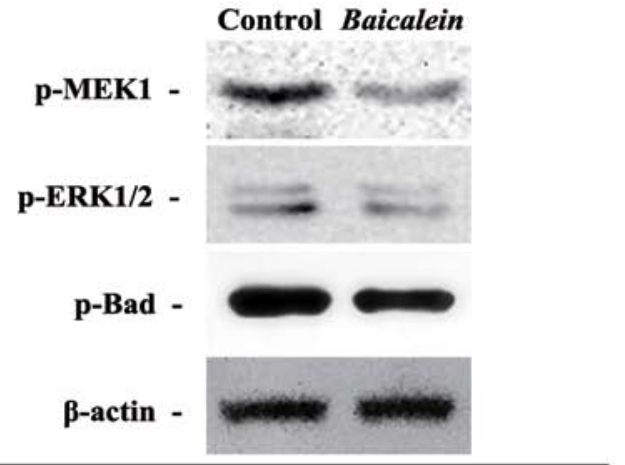

C Phosphorylation density (\%)

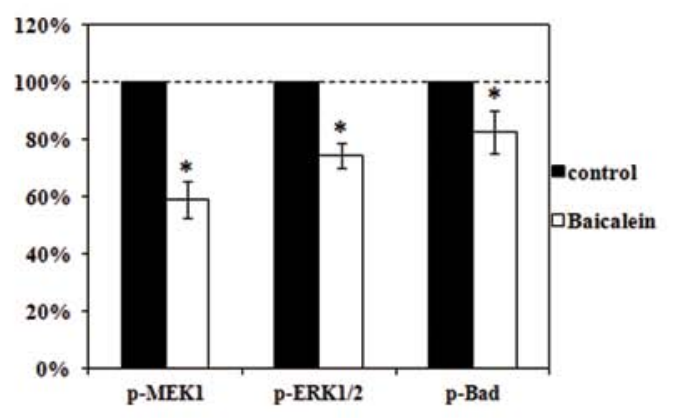

Figure 6. Baicalein downregulates MAPK/ERK signaling and induces apoptosis in xenograft tumors. (A) TUNEL assay and immunohistochemical staining of phospho-MEK1, phospho-ERK1/2 in xenograph tumors. A HepG x $_{2}$ xenograft model was established as described in Materials and methods. Mice were treated with or without Baicalein $10 \mathrm{mg} / \mathrm{kg} /$ day for 21 days. FFPE sections were prepared from control-treated and Baicalein-treated tumors. TUNEL assay and immunohistochemical staining were carried out on the sections as described in Materials and methods. (B) Western blot analysis of phospho-MEK1, phospho-ERK1/2 and phospho-Bad in xenograph tumors. Total lysates were prepared from the $\mathrm{HepG}_{2}$ xenograft tumors that were described in (A). (C) Quantitation of the levels of phospho-MEK1, phospho-ERK1/2 and phospho-Bad shown in (B). ${ }^{*}$ p $<0.05$ vs control group.

signaling apoptosis (27), the mechanisms and pathways involved in Baicalein-induced apoptosis on HCC cells are still unclear. Our data illustrated a decrease of MMP $\Delta \psi \mathrm{m}$ and released of cytochrome $c$ from mitochondria, and the following activation of caspase- 9 and caspase-3, suggesting a mitochondrial signaling-related apoptosis was induced by Baicalein in HCC cells. We have further demonstrated that induction of apoptosis is important for Baicalein effect. z-VAD-fmk is a pan-caspases inhibitor which could nullify caspases activity (28). Our results confirmed that $\mathrm{z}$-VAD-fmk did blocked Baicalein effects, suggesting that caspase-dependent apoptotic pathways were involved in Baicalein-induced inhibition on HCC cells.

The exact molecular mechanism by which Baicalein inhibits cell growth is still not known. There are few studies suggesting that MEK-ERK pathway could be the downstream signaling in response to Baicalein (29-31). Our study has demonstrated that inhibition of MEK-ERK pathway is critical for Baicalein action in HCC. The experiments of MEK overexpression showed that without inhibition of MEK-ERK pathway, Baicalein-induced growth inhibition was significantly attenuated. In fact, extracellular signal-regulated kinase (ERK) kinase (MEK)/ERK cascade plays critical roles in the development of HCC (32). ERK is a serine/threonine kinase that can be activated by hepatocyte growth factor (HGF) (33) and its receptor the c-Met proto-oncogene (34). ERK is activated in $\mathrm{HepG}_{2}$ cells after treatment with HGF and constitutive expres- sion of Ha-Ras $(35,36)$. ERK inhibitor is suggested as a potential anti-HCC agent (37-39). Sorafenib is the first targeted therapy drug that has demonstrated an improved overall survival benefit in patients with advanced HCC (40-42). Sorafenib can inhibit tumor cell proliferation in vitro by targeting the Raf/MEK/ ERK signaling pathway at the level of Raf kinase (43) and by targeting angiogenesis (44). p-ERK could be a useful biomarker predictive of sensitivity to sorafenib (45), suggesting the critical role of the MAPK/ERK signaling in HCC. Again, our study supports the notion that down-regulation of the MAPK/ERK activity is beneficial in HCC treatment.

$\mathrm{Bad}$ is a pro-apoptotic protein and its function is modulated by phosphorylation at two sites, Ser-112 and Ser-136 $(46,47)$. the MAPK-activated pp90-ribosomal S6 kinase family can catalyze the phosphorylation of Bad Ser-112 (48). The Ras-MAPK pathway is involved in the phosphorylation of Bad Ser-112 and its function related to dissociation of Bad from Bcl-xL (49). Underphosphorylated Bad interacts with antiapoptotic Bcl-2 members and anchors on the mitochondria to induce apoptosis whereas phosphorylated Bad is sequestered in the cytoplasm by 14-3-3 proteins that attenuate Bad induced apoptosis (50). Our results indicate that Baicalein downregulates the phosphorylation level of Bad, suggesting that Bad is one of the downstream targets of Baicalein-induced inhibition of ERK. Baicalein-induced apoptosis in hepatocellular cells could be through Bad-related regulation, which needs to be further determined. 
Taken together, this study found that Baicalein is an effective anti-HCC agent with low cytotoxicity to normal liver cells. This study provides evidence to show that inhibition of MAPK-ERK signaling and induction of intrinsic apoptosis are the critical mechanisms by which Baicalein inhibits HCC growth.

\section{Acknowledgements}

This study was supported by a grant from Program for Changjiang Scholars and Innovative Research Team in University (PCSIRT: 1171) and the Kwang-Hua Education Foundation of Xi'an Jiaotong University.

\section{References}

1. Siegel R, Ward E, Brawley O and Jemal A: Cancer statistics, 2011: The impact of eliminating socioeconomic and racial disparities on premature cancer deaths. CA Cancer J Clin 61: 212-236, 2011.

2. Zhang Y, Wang S, Li D, et al: A systems biology-based classifier for hepatocellular carcinoma diagnosis. PLoS One 6: e22426, 2011.

3. Almogy G, Lieberman S, Gips M, et al: Clinical outcomes of surgical resections for primary liver sarcoma in adults: results from a single centre. Eur J Surg Oncol 30: 421-427, 2004.

4. Livraghi T, Makisalo H and Line PD: Treatment options in hepatocellular carcinoma today. Scand J Surg 100: 22-29, 2011

5. Li ZF, Wang ZD, Ji YY, et al: Induction of apoptosis and cell cycle arrest in human HCC MHCC97H cells with Chrysanthemum indicum extract. World J Gastroenterol 15: 4538-4546, 2009

6. Wang ZD, Huang C, Li ZF, et al: Chrysanthemum indicum ethanolic extract inhibits invasion of hepatocellular carcinoma via regulation of MMP/TIMP balance as therapeutic target. Oncol Rep 23: 413-421, 2010.

7. Motoo Y and Sawabu N: Antitumor effects of saikosaponins, baicalin and baicalein on human hepatoma cell lines. Cancer Lett 86: 91-95, 1994.

8. Matsuzaki Y, Kurokawa N, Terai S, Matsumura Y, Kobayashi N and Okita K: Cell death induced by baicalein in human hepatocellular carcinoma cell lines. Jpn J Cancer Res 87: 170-177, 1996.

9. Farazi PA and DePinho RA: Hepatocellular carcinoma pathogenesis: from genes to environment. Nat Rev Cancer 6: 674-687, 2006.

10. Gailhouste L, Ezan F, Bessard A, et al: RNAi-mediated MEK1 knock-down prevents ERK1/2 activation and abolishes human hepatocarcinoma growth in vitro and in vivo. Int J Cancer 126 1367-1377, 2010.

11. Scudiero DA, Shoemaker RH, Paull KD, et al: Evaluation of a soluble tetrazolium formazan assay for cell-growth and drug sensitivity in culture using human and other tumor-cell lines. Cancer Res 48: 4827-4833, 1988.

12. Yang GY, Liao J, Kim K, Yurkow EJ and Yang CS: Inhibition of growth and induction of apoptosis in human cancer cell lines by tea polyphenols. Carcinogenesis 19: 611-616, 1998.

13. Tang W, Liu HW, Zhao WM, Wei DZ and Zhong JJ: Ganoderic acid T from Ganoderma lucidum mycelia induces mitochondria mediated apoptosis in lung cancer cells. Life Sci 80: 205-211, 2006

14. Li L, Lu QH, Shen YW and Hu X: Schisandrin B enhances doxorubicin-induced apoptosis of cancer cells but not normal cells. Biochem Pharmacol 71: 584-595, 2006.

15. Li ZF, Jiang A, Zhang S, et al: miR-615-3p promotes the phagocytic capacity of splenic macrophages by targeting ligand-dependent nuclear receptor corepressor in cirrhosisrelated portal hypertension. Exp Biol Med (Maywood) 236: 672-680, 2011

16. Brunnemann C, Weiger TM, Langeluddecke C, et al: Ethanol depolarizes the membrane potential and changes the cell volume of pituitary tumor cells (Gh3). Alcohol Clin Exp Res 34: 125a-125a, 2010.

17. Fang XJ, Yu SX, Eder A, et al: Regulation of BAD phosphorylation at serine 112 by the Ras-mitogen-activated protein kinase pathway. Oncogene 18: 6635-6640, 1999.
18. Deak JC and Templeton DJ: Regulation of the activity of MEK kinase 1 (MEKK1) by autophosphorylation within the kinase activation domain. Biochem J 322: 185-192, 1997.

19. Ikemoto S, Sugimura K, Yoshida N, et al: Antitumor effects of Scutellariae radix and its components baicalein, baicalin, and wogonin on bladder cancer cell lines. Urology 55: 951-955, 2000.

20. Ye F, Wu J, Dunn T, Yi J, Tong XD and Zhang D: Inhibition of cyclooxygenase-2 activity in head and neck cancer cells by genistein. Cancer Lett 211: 39-46, 2004.

21. Yu J, Liu H, Lei J, Tan W, Hu X and Zou G: Antitumor activity of chloroform fraction of Scutellaria barbata and its active constituents. Phytother Res 21: 817-822, 2007.

22. Du GJ, Han G, Zhang S, et al: Baicalin suppresses lung carcinoma and lung metastasis by SOD mimic and HIF-1 alpha inhibition. Eur J Pharmacol 630: 121-130, 2010.

23. Chen CH, Huang LLH, Huang CC, Lin CC, Lee Y and Lu FJ: Baicalein, a novel apoptotic agent for hepatoma cell lines: a potential medicine for hepatoma. Nutr Cancer 38: 287-295, 2000.

24. Han KH, Kim BK, Park JY, et al: Long-term clinical outcomes of hepatic arterial infusion chemotherapy with cisplatin with or without 5-fluorouracil in locally advanced hepatocellular carcinoma. J Cancer Res Clin 137: 659-667, 2011.

25. Hoffman RM, Rashidi B, An ZL, et al: Efficacy of intrahepatectomy 5-FU on recurrence and metastasis of human hepatocellular carcinoma in nude mice. Int J Cancer 91: 231-235, 2001

26. Bose Dasgupta S, Das BB, Sengupta S, et al: The caspase-independent algorithm of programmed cell death in Leishmania induced by baicalein: the role of LdEndoG, LdFEN-1 and LdTatD as a DNA 'degradesome'. Cell Death Differ 15: 1629-1640, 2008.

27. Elmore S: Apoptosis: a review of programmed cell death. Toxicol Pathol 35: 495-516, 2007.

28. Casares N, Pequignot MO, Tesniere A, et al: Caspase-dependent immunogenicity of doxorubicin-induced tumor cell death. J Exp Med 202: 1691-1701, 2005.

29. Li HB, Jiang Y and Chen F: Separation methods used for Scutellaria baicalensis active components. J Chromatogr B Analyt Technol Biomed Life Sci 812: 277-290, 2004.

30. Ma Z, Otsuyama K, Liu SQ, et al: Baicalein, a component of Scutellaria radix from Huang-Lian-Jie-Du-Tang (HLJDT), leads to suppression of proliferation and induction of apoptosis in human myeloma cells. Blood 105: 3312-3318, 2005.

31. Ye F, Che YF, McMillen E, et al: The effect of Scutellaria baicalensis on the signaling network in hepatocellular carcinoma cells. Nutr Cancer 61: 530-537, 2009.

32. Hui LJ, Min LH and He BK: Mitogen-activated protein kinases in hepatocellular carcinoma development. Semin Cancer Biol 21: 10-20, 2011.

33. Lu SC, Yang HP, Magilnick N, Noureddin M and Mato JM: Effect of hepatocyte growth factor on methionine adenosyltransferase genes and growth is cell density-dependent in HepG2 cells. J Cell Physiol 210: 766-773, 2007.

34. Dong JH, Xie B, Xing RX, et al: Down-regulation of c-Met expression inhibits human HCC cells growth and invasion by RNA interference. J Surg Res 162: 231-238, 2010.

35. Tsukada Y, Miyazawa K and Kitamura N: High intensity ERK signal mediates hepatocyte growth factor-induced proliferation inhibition of the human hepatocellular carcinoma cell line HepG2. J Biol Chem 276: 40968-40976, 2001.

36. Han JH, Tsukada Y, Hara E, Kitamura N and Tanaka T: Hepatocyte growth factor induces redistribution of p21(CIP1) and p27(KIP1) through ERK-dependent p16(INK4a) up-regulation, leading to cell cycle arrest at G(1) in HepG2 hepatoma cells. J Biol Chem 280: 31548-31556, 2005.

37. O'Neil BH, Goff LW, Kauh JSW, et al: Phase II study of the mitogen-activated protein kinase $1 / 2$ inhibitor selumetinib in patients with advanced hepatocellular carcinoma. J Clin Oncol 29: 2350-2356, 2011.

38. Klein PJ, Schmidt CM, Wiesenauer CA, et al: The effects of a novel MEK inhibitor PD184161 on MEK-ERK signaling and growth in human liver cancer. Neoplasia 8: 1-8, 2006.

39. Kuo TC, Lu HP and Chao CCK: The tyrosine kinase inhibitor sorafenib sensitizes hepatocellular carcinoma cells to taxol by suppressing the HURP protein. Biochem Pharmacol 82: 184-194, 2011.

40. Shen Y, Hsu C, Hsu C, et al: A phase II study of sorafenib in combination with tegafur/uracil (UFT) for Asian patients with advanced hepatocellular carcinoma (HCC). J Clin Oncol 27: 4589,2009 . 
41. Abou-Alfa GK, Schwartz L, Ricci S, et al: Phase II study of sorafenib in patients with advanced hepatocellular carcinoma. J Clin Oncol 24: 4293-4300, 2006.

42. Wang SH, Huang X, Li Y, et al: RN181 suppresses hepatocellular carcinoma growth by inhibition of the ERK/MAPK pathway. Hepatology 53: 1932-1942, 2011.

43. Takezawa K, Okamoto I, Yonesaka K, et al: Sorafenib inhibits non-small cell lung cancer cell growth by targeting B-RAF in KRAS wild-type cells and C-RAF in KRAS mutant cells. Cancer Res 69: 6515-6521, 2009.

44. Wilhelm SM, Adnane L, Newell P, Villanueva A, Llovet JM and Lynch M: Preclinical overview of sorafenib, a multikinase inhibitor that targets both Raf and VEGF and PDGF receptor tyrosine kinase signaling. Mol Cancer Ther 7: 3129-3140, 2008

45. Zhang Z, Zhou XY, Shen HJ, Wang DX and Wang YH: Phosphorylated ERK is a potential predictor of sensitivity to sorafenib when treating hepatocellular carcinoma: evidence from an in vitro study. BMC Med 7: 41, 2009.
46. Zha JP, Harada H, Yang E, Jockel J and Korsmeyer SJ: Serine phosphorylation of death agonist BAD in response to survival factor results in binding to 14-3-3 not BGL-X(L). Cell 87: 619-628, 1996.

47. Datta SR, Dudek H, Tao X, et al: Akt phosphorylation of BAD couples survival signals to the cell-intrinsic death machinery. Cell 91: 231-241, 1997.

48. Bonni A, Brunet A, West AE, Datta SR, Takasu MA and Greenberg ME: Cell survival promoted by the Ras-MAPK signaling pathway by transcription-dependent and -independent mechanisms. Science 286: 1358-1362, 1999.

49. Scheid MP, Schubert KM and Duronio V: Regulation of bad phosphorylation and association with $\mathrm{Bcl}-\mathrm{x}(\mathrm{L})$ by the MAPK/Erk kinase. J Biol Chem 274: 31108-31113, 1999.

50. Xing HM, Zhang SS, Weinheimer C, Kovacs A and Muslin AJ: 14-3-3 proteins block apoptosis and differentially regulate MAPK cascades. EMBO J 19: 349-358, 2000. 